\title{
ACESSIBILIDADE CULTURAL
}

\section{Entrevistada:}

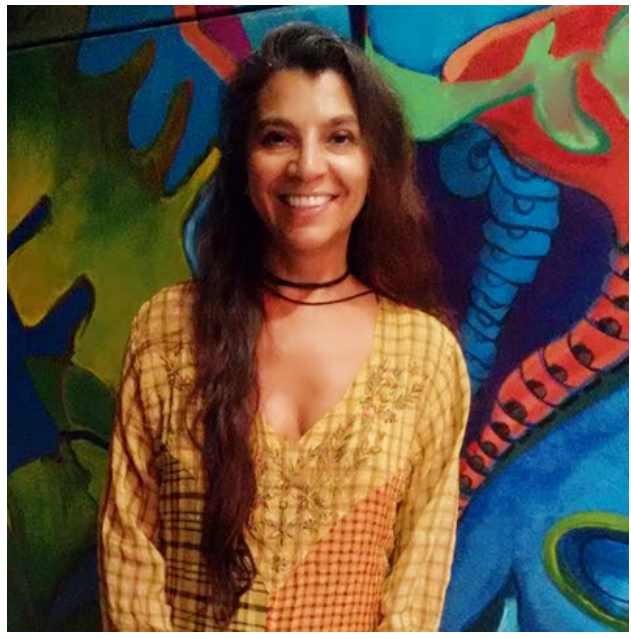

Patrícia Silva Dorneles - Possui graduação em terapia ocupacional pela Federação das Faculdades Metodistas do Sul Instituto Porto Alegre (1995). É mestre em educação (2001) pela Universidade Federal de Santa Catarina (UFSC), na linha de pesquisa educação popular e movimentos sociais; doutora em geografia (2011) pela Universidade Federal do Rio Grande do Sul (UFRGS), na linha ambiente, ensino e território; e pós-doutora em terapia ocupacional pela Universidade Federal de São Carlos (UFSCar). Foi idealizadora e é a atual coordenadora do Curso de Especialização em Acessibilidade Cultural da Universidade Federal do Rio de Janeiro (UFRJ). É superintendente de Difusão Cultural do Fórum de Ciência e Cultura da UFRJ. Atua há mais de 20 anos no campo das políticas públicas culturais. patricia.dorneles.ufrj@gmail. com

\section{Entrevistadora:}

Desirée Nobre Salasar - Possui graduação em terapia ocupacional pela Universidade Federal de Pelotas (2017). É mestranda em Memória Social e Patrimônio Cultural pela mesma instituição. Realizou estágio em Acessibilidade Cultural no Museu da Comunidade Concelhia da Batalha, Portugal (2015). Atuou como bolsista e colaboradora do Programa de Extensão O Museu do Conhecimento para Todos (2012 - 2016). Responsável pelo Programa de Acessibilidade do Museu do Doce da UFPel e pelo Plano de Acessibilidade da Pró-Reitoria de Extensão e Cultura.dnobre.to@gmail.com 


\section{RESUMO}

Nesta entrevista, realizada com Patricia Dorneles, coordenadora do curso de especialização em Acessibilidade Cultural e responsável pela sua criação e implementação, são respondidas algumas perguntas sobre o curso, o estado da arte da acessibilidade cultural no Brasil, as políticas públicas culturais e a Rede Interinstitucional, atualmente composta pela Universidade do Rio de Janeiro, Universidade do Rio Grande do Norte, Universidade Federal do Rio Grande do Sul e Universidade Federal de Pelotas. Objetiva-se apresentar o campo da acessibilidade cultural e discutir o processo histórico desta pauta dentro do curso de especialização e suas conquistas.

Palavras-chave: Acessibilidade Cultural. Pessoa com deficiência. Políticas Públicas Culturais.

\section{ABSTRACT}

In this interview with Patricia Dorneles, coordinator of the specialization course on Cultural Accessibility and responsible for its creation and implementation, some questions are answered about the course, the state of the art of cultural accessibility in Brazil, cultural public policies and the Interinstitutional Network, currently composed of the University of Rio de Janeiro, the University of Rio Grande do Norte, the Federal University of Rio Grande do Sul and the Federal University of Pelotas. It aims to present the field of cultural accessibility and discuss the historical process of this agenda within the course of specialization and its achievements.

Keywords: Cultural Accessibility. Disabled person. Cultural Policies.

\section{1- PARA VOCÊ O QUE SÃO CULTURAS ACESSÍVEIS?}

Acho que no primeiro momento esta pergunta nos provoca a pensar em culturas acessíveis e a pauta da acessibilidade cultural, da qual a gente atua na perspectiva da pessoa com deficiência. Assim, nesta linha de raciocínio, vamos pensar que as manifestações estéticas, artísticas e de identidade cultural, estas últimas, provocadas por um olhar sócio-antropológico sobre manifestações culturais, devem ser acessíveis no sentido de se promover uma qualidade de transmissão, comunicação e diálogo entre as pessoas com deficiência e estes conteúdos culturais. Tanto aqueles conteúdos que se encontram nos espaços e ou ambientes culturais, como os que não estão. Desta forma, inicialmente, a pergunta poderia nos provocar a pensar que culturas acessíveis são isto, pois caberia 
para a pauta que a gente atua, a acessibilidade cultural para pessoas com deficiência. Mas, particularmente, acredito que culturas acessíveis deva ser maior do que isso. O conceito de acessibilidade cultural identificado a partir da atuação junto à pessoas com deficiência, vai surgir concomitante às políticas culturais no ano de 2008, quando foi realizada a Oficina Nacional de Políticas Públicas para Pessoas com Deficiência. Nesta oficina, o termo acessibilidade cultural foi apresentado aos gestores do Ministério da Cultura daquele período como um elemento fundamental para pensar a questão da relação das políticas culturais e as pessoas com deficiência, para além das políticas de fomento, de patrimônio e de difusão das suas produções. Naquele período o termo acessibilidade cultural se constitui em um conceito, e o mesmo manteve a identidade traduzida por muito tempo como um conceito único e direcionando a expressão acessibilidade cultural para pessoas com deficiência junto às políticas culturais. Então, quando falamos sobre o que são culturas acessíveis, eu acredito que a gente deva pensar através de uma visão mais ampliada, da qual a acessibilidade cultural para pessoas com deficiência se faça presente, mas não seja reduzida apenas sobre o olhar deste público, ou grupo de pessoas. Desta maneira, gosto de pensar que culturas acessíveis são a democratização cultural. Se nós olharmos para o processo histórico, da construção das políticas culturais no Brasil, a gente vai perceber que dos anos noventa, com a abertura política, ocorre uma transformação nos paradigmas de tudo o que envolve, de certa forma, a perspectiva de relação com o fazer, ensinar, difundir e fomentar o acesso à arte e à cultura. Neste sentido, se iniciam processos importantes sobre um campo qualificado, a ser construído, da temática cultural junto às politicas públicas. Desta forma, ocorrem esforços para que o acesso à cultura rompa com a marca de uma diferença de classe, em relação àqueles que têm mais capital cultural que os outros, pela ausência de um estado descomprometido de sua função de promoção de cidadania. Há uma retomada de sentido de vida pública que mobiliza os trabalhadores, os arte-educadores e os educadores populares a iniciar um processo de democratização cultural a partir de suas iniciativas junto aos movimentos de base comunitária, transformando as relações do fazer estético artístico com potencialidades capazes de provocar novas relações de identidade cultural, novas relações com a cidade e com o espaço urbano. E o que isso significou nos anos noventa? Um impacto importante em construções de políticas culturais que priorizassem o acesso a arte e a novos conhecimentos culturais de pessoas que, até então, tinham uma relação mais restrita devido ao pouco caso de uma política de estado em relação à pauta, onde os temas culturais eram traduzidos com uma certa superficialidade para a vida de um modo geral. Este processo de democratização cultural ou de democratização da cultura fomenta diferentes ações e projetos de aproximação do fazer estético-artístico e cultural, bem como com os conteúdos culturais instituídos e tradicionais. Nesta perspectiva, acredito que quando somos provocados a pensar culturas acessíveis, a gente deve lembrar-se do processo de democratização cultural, que avançou, junto à questão da construção de democracia no Brasil. Isto 
foi possível, também, pela presença de diferentes intelectuais orgânicos, que atuaram em diferentes escalas para o avanço da democratização cultural. A partir deste contexto surge com força o termo "oficineiros" ou a constituição das oficinas de arte, que aparecem e são retomadas como um campo mais aberto de um processo de aprendizado e de vivência em arte. Neste momento da construção da democratização cultural no Brasil, dois conceitos têm sido referências importantes junto às políticas nacionais. O primeiro é o conceito de Descentralização da Cultura, desenvolvido pelo Luiz Pilla Vares, secretário de cultura de Porto Alegre na gestão da Administração Popular desta cidade nos anos noventa e o segundo, mas não menos importante, é o conceito de Cidadania Cultural, desenhado por Marilena Chauí, na gestão da Administração Popular de São Paulo no mesmo período. Este último se solidificou como uma referência importante e ainda hoje, tem traduzido nossas perspectivas de qualidade de uma política cultural, democrática e de direitos. Desta forma, quando se fala em culturas acessíveis temos que expandir para além das pessoas com deficiência. É preciso pensar em todos os públicos. Pessoas em vulnerabilidade social, pessoas em sofrimento psíquico, pessoas em processo de desfiliação do Estado. Enfim, todas as pessoas que estão em processo de exclusão cultural. Temos que fomentar novas identidades inventivas. Preservar, valorizar e difundir todas as manifestações culturais. Circular e intercambiar saberes, fazeres e práticas. Concluindo, creio que culturas acessíveis sejam desafios de uma qualidade de mediação e troca de todos os conteúdos culturais e de todas as produções artísticas, estéticas, de identidade e território culturais para todas as pessoas. Acredito que temos que retomar esta perspectiva da democratização da cultura e, na atual conjuntura em que vivemos, a palavra democracia deve que estar presente em nossos discursos e estar efetivamente sendo realizada em nossas práticas.

\section{2- A UFRJ TEM UM PROTAGONISMO IMPORTANTE ATRAVÉS DO CURSO DE ESPECIALIZAÇÃO EM ACESSIBILIDADE CULTURAL, VOCÊ PODERIA CONTAR COMO FOI O PROCESSO DE IMPLEMENTAÇÃO DO CURSO?}

O curso surgiu através de uma demanda da sociedade civil, que vinha pautando junto a vários debates a importância de uma formação geral na perspectiva da deficiência e cultura. Assim, a Secretaria de Identidade e Diversidade Cultural, na qual o ator Sérgio Mamberti era o secretário na época do Governo Lula, organizou a Oficina Nacional de Políticas Públicas Culturais para Pessoas com Deficiência, que foi realizada em parceria com a Fiocruz- RJ. O objetivo desta oficina foi construir ações e diretrizes para orientar uma política de cultura para pessoas com deficiência. Cerca de 60 pessoas se reuniram na cidade do Rio de Janeiro e dentre o público estavam pessoas com deficiência que trabalhavam na pauta da cultura e da arte e pessoas sem deficiência, mas que atuavam em prol da cidadania cultural destes primeiros. Os participantes apontaram, nesta ofici- 
na, a importância de ter uma formação na perspectiva da acessibilidade cultural. É neste contexto em que o curso surge. Na época eu trabalhava no Ministério da Cultura (MINC) e quando fui para a Universidade Federal do Rio de Janeiro, para ser professora do curso de Terapia Ocupacional, lembrei-me desta necessidade e como eu sou uma pessoa que milito e atuo há muitos anos em gestão pública de cultura, achei que seria importante a gente ter essa iniciativa de implementar uma formação abrangente, que trouxesse conteúdos diversificados e interdisciplinares para a construção de um pensamento e de sensibilização para efetivar a política nacional de cultura em prol das pessoas com deficiência. O objetivo do curso é formar gestores públicos para que implementem a política nacional de cultura, formar professores universitários de uma forma ampliada nesta temática da acessibilidade, para que se incluam a disciplina de acessibilidade cultural nos currículos de cursos. Tanto nos currículos de artes, nas licenciaturas, nos bacharelados, como de produção cultural, de terapia ocupacional ou outros cursos afins, que se identificam com a pauta da inclusão. Também formar o terceiro setor para que façam o controle social junto às conferências nacionais, estaduais e municipais de cultura e junto aos conselhos municipais de cultura, para que sejam implementadas a política nacional e as pautas de acessibilidade nos ambientes culturais. Do mesmo modo, há a capacitação para os pontos de cultura, que são ligados à secretaria que nos apoia (Secretaria de Identidade e Diversidade Cultural), porque eles estão na base, no território e a gente sabe que $70 \%$ da população com deficiência vive em vulnerabilidade social. Desta forma, o Ponto de Cultura pode ser a primeira porta de entrada para estas pessoas, para a sua vivência cultural, para produzir, ter acesso e dialogar com as experiências estéticas e artísticas na área da cultura.

\section{3- COMO VOCÊ AVALIA OS TRABALHOS DESENVOLVIDOS PELAS PRI- MEIRAS TURMAS E QUAIS FORAM AS CONTRAPARTIDAS QUE OS ALU- NOS JÁ CONSEGUIRAM DESENVOLVER EM SEUS ESTADOS?}

A primeira grande contribuição destas turmas, são os cerca de setenta e sete trabalhos de conclusão de curso. Esta é a primeira grande levada de sistematização que a gente tem no país em termos de quantidade de grupo e de identidade, de pesquisa em acessibilidade cultural. Os temas são os mais diversos. A gente tem pessoas que fizeram seus trabalhos em cima dos ambientes culturais, de políticas públicas, de linguagens artísticas e estéticas e sobre a relação com a promoção da cidadania cultural. Há uma grande diversidade de trabalhos, bem interessante neste quesito da produção científica acadêmica, que acredito ser a grande contribuição primeira das duas turmas. 0 curso tem como característica oferecer uma formação técnica-política de ação cultural freireana, ou seja, que cria não só a formação, mas a partir da formação produz um engajamento, um compromisso de multiplicar esse conhecimento. Desta forma há contribuições de 
ambas as turmas que dizem respeito a esta militância e engajamento na multiplicação da pauta. Na primeira turma fizemos a Conferência Livre de Acessibilidade Cultural, da qual nos propomos noventa propostas para levar para a Conferência Nacional de Cultura, onde conseguimos representatividade de quatro delegados. Os nossos alunos foram para as conferências municipais e estaduais com essas noventa propostas e as colocaram na pauta das conferências de ambas as esferas, fazendo com que as mesmas ganhassem força até chegar à Conferência Nacional de Cultura. Assim, conseguimos aprovar a meta 3.18 como prioritária do quarto eixo, que era sobre direitos humanos e cultura. Acredito que esta também é uma grande contribuição que nós temos enquanto curso, articulando politicamente e criando esta importante mobilização. Outra situação também relevante, foi a realização conjunta do II Encontro Nacional de Acessibilidade Cultural - ENAC, ao TEIA - Encontro Nacional dos Pontos de Cultura, que ocorreu na cidade de Natal, em 2014. O ENAC, que é promovido pela UFRJ, e o III Seminário Nacional de Acessibilidade em Ambientes Culturais- SENAC, promovido pela UFRGS, aconteceram de forma integrada durante o TEIA. A ação a ser destacada é que o curso e este projeto criaram um abaixo assinado para a inserção da Libras na política do audiovisual brasileira. Outra grande contribuição ocorreu a partir de uma parceria que fizemos com a UFRGS e que foi desenvolvida pela segunda turma. Os discentes do curso de pós-graduação participaram da formação do curso de extensão da UFRGS, EAD de 40 horas, chamado de Acessibilidade em Ambientes Culturais e depois se tornaram monitores do curso para um público externo. A UFRGS geralmente abre este curso para 30 pessoas, porém com o auxílio dos nossos alunos, foi possível capacitar 420 pessoas. Desta forma, multiplicamos muito mais que $100 \%$, através da força dos nossos alunos, que realizando a monitoria, capacitaram e multiplicaram este conhecimento. Esta foi uma grande contribuição que a turma e o projeto construíram em termos de engajamento e de responsabilidade de ampliação da pauta. Nós pretendemos, ainda este ano, dar início a um mapeamento das ações realizadas pelos nossos alunos, mas o que a gente vê hoje é que muitos ex-alunos estão executando este trabalho de multiplicar nas políticas públicas e no campo da docência, através da criação de disciplinas de acessibilidade cultural em seus cursos. Temos como exemplo, a experiência da disciplina "Produção Cultural Acessível” do curso de Produção Cultural do Instituto Federal do Rio de Janeiro (IFRJ) e dentro da UFRJ a disciplina "Gastronomia Acessível" do curso de Gastronomia e a disciplina "Acessibilidade Cultural" no curso de Terapia Ocupacional. Há uma diversidade de experiências que os ex-alunos estão aplicando, ou seja, este resultado é muito significativo. As pessoas estão se capacitando conosco e multiplicando este conhecimento, através de várias intervenções nas suas instituições de origem ou em outros projetos que estão associados em uma rede de trabalho. Outra conquista importante que a gente teve, a partir desta ação, é a própria política do governo federal, que também começou a ampliar a temática dentro da política nacional e no próprio Programa Cultura Viva. Como nós temos os Pontos de Cultura envolvidos junto à 
pauta da acessibilidade cultural, atualmente há uma rubrica específica de acessibilidade para os projetos ligados aos Pontos de Cultura e ao Programa.

\section{4- COMENTE A PARTICIPAÇÃO DE PESSOAS COM DEFICIÊNCIA NAS PRIMEIRAS TURMAS.}

Na primeira turma, em 2013, nós tivemos duas pessoas com deficiência, uma que fazia uso da cadeira de rodas e o outro que tinha uma deficiência auditiva, mas usava um implante, então se comunicava sem intérprete de Libras. Na segunda turma, em 2015, só havia uma pessoa com deficiência, que também fazia uso da cadeira de rodas. Nesta terceira turma, que iniciamos este ano, nós temos o desafio de ter uma pessoa surda e uma pessoa com deficiência visual. Este é o nosso desafio agora: desenvolver a acessibilidade para este grupo novo que traz a demanda da Libras e da audiodescrição. Destacamos que é muito importante que pessoas com deficiência participem desta formação. A gente estimula e espera isso, porque há muitos artistas com deficiência e a gente acredita que o melhor mediador da acessibilidade cultural são as próprias pessoas com deficiência. Desta forma, a participação deles é muito rica, porque eles vêm com uma realidade concreta das barreiras, de todo um histórico de vida e de luta e nos desafiam, em sua presença, a todo o momento em como que a gente deve, de fato, realizar todos os níveis de acessibilidade, desde a atitudinal, a comunicacional, arquitetônica... todas as acessibilidades que são importantes para a gente estar pensando com eles. Assim, é de suma relevância a participação das pessoas com deficiência no curso.

\section{5- A terceira turma do curso terá seu início ainda este ano. Quais são as expectativas para esta turma?}

A expectativa que a gente tem para esta turma é a mesma que tivemos com as anteriores, ou seja, uma turma colaborativa com muitas trocas de experiências. Que seja uma turma animada, com engajamento na pauta, que nos ajudem a fortalecer e construir a política de acessibilidade cultural no Brasil e que fortaleçam as conquistas que até então nós já tivemos. Que seja uma turma provocativa, criativa e que esteja conosco nesta dedicação à promoção da acessibilidade cultural para as pessoas com deficiência. Uma turma bem diversa, como todas as outras foram, com gestores públicos, com representantes de Ponto de Cultura, de organização do terceiro setor e professores universitários. Estas categorias e suas distribuições por estados provocam uma diversidade muito grande da turma, em nível de formação, de identidade cultural e de experiências, tanto nas áreas de políticas culturais quanto na inclusão de pessoas com deficiência. Para nós, também é muito importante esta promoção do encontro da diversidade 
de olhares, experiências, de identidades territoriais e de experiências culturais. Eu sempre digo que a turma é a segunda formação do próprio curso, pois a troca é muito intensa em decorrência destes deslocamentos que são provocados pela diversidade. Assim, acredito que será uma turma muito rica, como todas as outras. Este ano, em cima de uma demanda do Ministério da Cultura e também já de uma pauta que muito nos foi solicitada nos anos anteriores, houve a inclusão da categoria de produtor cultural. Portanto este ano nós temos um número bem expressivo de produtores culturais que vêm participar do curso de especialização.

\section{6- PARA VOCÊ, EM QUE MOMENTO SE ENCONTRA A ACESSIBILIDADE CULTURAL NO PAÍS?}

Acho que a gente ainda tem que avançar muito, mas temos algumas conquistas. Em termos de legislação o país é rico, isso já se sabe e sempre se comentou. Temos a Constituição Federal e agora a Lei Brasileira de Inclusão e todos estes desafios que já se conseguiu na institucionalização da política nacional. Em termos de Ministério da Cultura e de política nacional de cultura foi possível avançar muito também, a exemplo da obrigatoriedade da acessibilidade nos projetos na Lei Rouanet, a importância do Tratado de Marraqueche, no qual o Brasil é signatário, que trata da liberação da reprodução de obras literárias, mas é preciso avançar na aplicabilidade destas legislações e normativas. Outro ponto relevante, diz respeito à acessibilidade no audiovisual brasileiro, onde já se consolidou esta pauta e, atualmente, o Brasil se tornou uma referência internacional nesta discussão. Claro que há sempre uma tencionalidade na disputa do campo para a aplicação efetiva dos recursos e conseguir implementação da lei, mas eu considero que a gente avançou bastante. A inclusão da rubrica de acessibilidade cultural, junto ao Programa Cultura Viva e aos Pontos de Cultura, também é um progresso. Temos experiências de fomento do Ministério da Cultura de editais de premiação para ações de acessibilidade cultural e recentemente o MinC lançou um grande edital nacional de várias áreas, onde incluiu a premiação de iniciativas que tenham em pauta a inclusão da pessoa com deficiência. O curso de especialização vem como um instrumento multiplicador e de impacto de fortalecimento da política e também com essa colaboração, conforme já falado anteriormente. Mas é preciso progredir na questão orçamentária. Eu vejo que agora todos os editais trazem a pauta da acessibilidade. Os editais de fomento cultural, principalmente os nacionais, exigem a acessibilidade cultural nos projetos, mas não colocaram um aporte significativo para o investimento na área. Isto vem criando um constrangimento entre os gestores e os produtores culturais junto à temática da acessibilidade, porque o orçamento para o projeto continua o mesmo, mas quando se inclui os recursos de acessibilidade, encarece o projeto. Sabemos que estes recursos são importantes, mas eles têm preços consideráveis e isso causa um impacto grande, o que acaba por dificultando a qualidade da 
implementação da acessibilidade nos projetos. Como consequência, o produtor acaba por não conseguir fazer a acessibilidade integral necessária para o projeto cultural, ou seja, ou ele investe na interpretação de Libras ou em audiodescrição, por exemplo. Então o avanço pelo qual temos que brigar agora, a nossa disputa e a nossa força deve ser para que se amplie o quesito de orçamento, para que os projetos culturais possam, de fato, oferecer todos os níveis de acessibilidade para as pessoas com deficiência. Já temos muito mais iniciativas culturais acessíveis, porque agora é lei, então foram ampliadas essas ações. As pessoas estão muito mais sensibilizadas para isso, estão mais comprometidas com esta questão. Mas nós precisamos ampliar muito mais, executar muito mais e principalmente lutar para a ampliação do orçamento para que a gente tenha a qualidade da política de acessibilidade cultural junto aos projetos e programas culturais. Faz-se necessário também expandir a capacitação em acessibilidade cultural, há de se investir em multiplicação, capacitação e sensibilização para que se amplie cada vez mais a ação e a pauta da acessibilidade cultural para pessoas com deficiência no país.

\section{7- PARA ALÉM DAS POLÍTICAS PÚBLICAS, O QUE VOCÊ ACHA QUE É FUNDAMENTAL PARA QUE SE TENHA A EFETIVAÇÃO DA ACESSIBILI- DADE CULTURAL?}

A mobilização da sociedade civil para que a política pública aconteça, mas principalmente, a articulação com as pessoas com deficiência, pois é muito importante que se tenha um investimento em público e plateia. Não podemos esquecer que as pessoas com deficiência passaram um longo período histórico em um processo de exclusão muito importante e que os espaços culturais não estavam atentos a receber estas pessoas. Assim, nem muito o espaço cultural está preparado para receber este público, nem as pessoas com deficiência não têm a concepção ou o conhecimento, ou ainda, não está introjetado nelas que cultura também é um direito. Durante muito tempo as pessoas com deficiência lutaram pelas políticas de educação, assistência, saúde, porém não há uma trajetória de luta pelas políticas culturais e o direito de fruição cultural, de cidadania cultural. Então, um grande investimento que nós temos que fazer é sensibilizar a sociedade civil, principalmente as pessoas com deficiência, para que estejam junto conosco, reivindicando a qualidade da efetivação da política pública cultural e de todas as outras instituições que de, certa forma, direta ou indiretamente se utilizam do recurso público, a partir de seus financiamentos de projetos via Lei Rouanet ou outras formas de incentivo, como desconto de imposto de renda ou de apoio de responsabilidade social. Desta forma é importante que se esteja atento à atuação junto à sociedade civil, de maneira a mobilizar e sensibilizar os grandes empresários para que eles auxiliem, tanto as políticas públicas, como o terceiro setor, a investir mais na implementação da acessibilidade cultural. Acredito que sejam estes os principais pontos: $O$ primeiro diz respeito à sensibilização 
da própria população com deficiência, no sentido de mobilizá-los para entender a cultura como direito e que eles podem reivindicar por isso e o fomento de trabalhar com público e plateia, trazendo cada vez mais esta população para estes espaços culturais. Já no segundo ponto, destaco a atuação junto às instituições e os espaços culturais, para que eles abracem a pauta, multipliquem e executem a legislação e talvez. Como sugestão, aponto que seria importante trabalhar com os grandes empresários através de uma política de incentivo para que se ampliem os recursos nas iniciativas de acessibilidade cultural para pessoas com deficiência.

\section{8- QUAL A IMPORTÂNCIA DA INTERDISCIPLINARIDADE PARA A PAUTA DE ACESSIBILIDADE CULTURAL?}

Eu acredito que a interdisciplinaridade é importante para todas as pautas, cada vez mais a gente tem que se dar conta que a ciência, os pontos de vista e os paradigmas diferenciados auxiliam na construção de um pensamento mais complexo, que permite uma flexibilidade na busca de soluções, de estratégias e da compreensão do mundo de uma forma mais democrática, inclusiva, que nos coloca nessa potência que é a vivência da diversidade. Em relação à acessibilidade cultural, eu acredito que a interdisciplinaridade é fundamental porque a inclusão da pessoa com deficiência exige diferentes olhares sobre a busca de recursos e instrumentos de mediação. Assim, a interdisciplinaridade é essencial. Veja como é a construção do nosso curso, que busca um pouco esta formação diversificada que cruza os olhares. Às vezes numa linguagem mais multidisciplinar, às vezes num olhar mais interdisciplinar, discutimos várias questões de acessibilidade e mediação cultural, de linguagens e instrumentos de mediação. A Terapia Ocupacional têm auxiliado na formação junto às tecnologias assistivas e outros recursos que são importantes e que fazem parte deste corpo de instrumentos de mediação, mas ao mesmo tempo também, a gente tem pessoas da área de Museologia, das políticas públicas culturais, da Pedagogia, que cuidam das ações educativas dos museus e estes intercâmbios com estas áreas qualificam o pensamento sobre a aplicabilidade dos instrumentos de mediação cultural. Então, nesse sentido, a interdisciplinaridade amplia os horizontes, traz as experiências de conhecimento. Por exemplo, sabemos que o pessoal que trabalha na área da cultura conhece tudo sobre gestão e implementação de políticas e projetos, mas não entende nada sobre as deficiências. As pessoas que trabalham com as deficiências, mas em contextos de reabilitação e busca da autonomia, que é um pouco da nossa área da Terapia Ocupacional, não têm a experiência do que é a aplicabilidade ou a implementação de políticas de cidadania cultural, ou seja, a inserção destas pessoas em ambientes culturais. Desta forma, eu acho que a interdisciplinaridade na pauta da acessibilidade cultural ela não é só fundamental, mas é ela que vem avançando conosco na qualificação e efetivação destes recursos. Cada vez mais 
o pessoal da área dos ambientes culturais, busca o intercâmbio, não só com as pessoas com deficiência, mas também com as pessoas que dominam os recursos de mediação e de linguagem, para qualificar a implementação do seu trabalho. Então, para pensar a acessibilidade cultural hoje, a gente precisa ter os arquitetos, os terapeutas ocupacionais, o pessoal que atua na gestão dos ambientes culturais. No caso dos museus, os museólogos, os educadores da ação educativa destes espaços e os produtores culturais. É nesta perspectiva que esta formação que nós trazemos é muito mais uma sensibilização, no sentido de qualificar o olhar sobre a pauta da acessibilidade cultural e as dificuldades e desafios da implementação da mesma. Sem a interdisciplinaridade não há avanço na construção da cidadania cultural das pessoas com deficiência.

\section{9- COMENTE SOBRE A REDE INTERINSTITUCIONAL DE ACESSIBILIDA- DE CULTURAL.}

Por enquanto eu gosto de pensar a Rede Interinstitucional de Acessibilidade Cultural, como uma Rede de Propostas, diz Cássio Martins, que discute "redes". Na verdade, ela junta algumas instituições parceiras que se fortalecem umas as outras no seu trabalho de implementação das políticas de acessibilidade e também na atuação conjunta na difusão desta temática, no sentido de pesquisa, ensino e extensão. É como se a gente tivesse um grupo de pessoas que se auxiliam e se fortalecem na coragem de continuar com este trabalho. Sabemos que temos grandes desafios, não só nas nossas instituições, mas também na sociedade como um todo. Por mais que a gente tenha avançado, ainda é um tema novo e precisamos nos qualificar muito mais para que a pauta da acessibilidade seja implementada com merece. Assim, a ideia da rede interinstitucional é juntar estes parceiros, que estão em outras universidades ou em outras instituições, para fazer intercâmbio em experiências, tecnologia e conhecimento, para qualificar as nossas ações e somar este trabalho. Por exemplo, a gente tem essa proposta da rede interinstitucional entre as universidades porque a UFRGS já tem um trabalho de ponta, no que diz respeito ao ensino à distância e também em pesquisas e execuções internas de trabalho. A UFPel também já tem um trabalho de ponta, porque tem uma identidade entre as universidades públicas como uma ação permanente de acessibilidade em um museu, que já usa dos recursos de acessibilidade, já é acessível e vêm cada vez mais se qualificando. A UFRJ, por exemplo, tem contribuído na implementação deste curso de pós-graduação. Ao mesmo tempo tem outras fragilidades institucionais onde não avançou ainda com uma efetivação permanente de acessibilidade ou de recursos de acessibilidade nos seus museus. A UFRN já tem todo um serviço de ensino à distância altamente qualificado e já promove acessibilidade, então tem expertise na questão da audiodescrição, formação à distância, de tradução destes conteúdos com todas as linguagens necessárias para que ele se torne acessível para todos. É nesta perspectiva que 
a gente vem constituindo esta rede colaborativa, no sentido de fortalecer o que uma instituição consegue se destacar e a outra ainda não conseguiu avançar. É mais ou menos por este viés que a rede está se formando, porém é preciso avançar mais na institucionalidade desta rede, capitar recursos comuns para que a rede se fortaleça e busque equilíbrio entre as diversas ações que cada um faz na sua instituição. Ou seja, nós temos que avançar na acessibilidade dos museus, as outras instituições podem multiplicar o curso de especialização nas suas regiões. A UFRJ precisa investir no ensino à distância e na preparação deste conteúdo, que é algo que a UFRGS e a UFRN já fazem com qualidade. A gente precisa aprender com a UFPel esta ousadia de ter um trabalho permanente e interdisciplinar constante dentro do espaço museal. A rede vem se fortalecendo como uma troca de experiência, um intercâmbio e de apoio. Acredito que ela tem se desenvolvido mais no sentido de apoio. Às vezes até um apoio moral, como a gente brinca, de saber que não estamos sós. E também acho significativo pensar a rede, no sentido de que juntos demonstramos que algumas universidades públicas, realmente estão atentas à pauta da acessibilidade cultural para as pessoas com deficiência. $E$ quando digo isso, eu não estou falando de conteúdo, das pessoas com deficiência sendo inseridas na universidade para fazerem seus cursos de graduação ou pós-graduação, porque isto também deve ser considerado acessibilidade cultural, já que a pessoa está se inserindo num campo de formação, para fazer sua formação profissional e acadêmica; mas estou querendo reafirmar a pauta da acessibilidade cultural como compromisso destas instituições de pensar suas políticas culturais, junto aos seus programas culturais, aos seus espaços e ambientes culturais.

Data de recebimento: 23 de agosto de 2018.

Data de aceite para publicação: 30 de agosto de 2018. 